\title{
Presencia histórica del fuego en el territorio Incendios históricos en la Comarca del Valle del Guadiato (Córdoba)
}

\author{
Lázaro ENTRENAS MARTíneZ ${ }^{1}$ \\ Departamento de Análisis Geográfico Regional y Geografía Física \\ Universidad Complutense de Madrid \\ LazaroEntrenas@gmail.com
}

Recibido: 21 de Enero de 2011

Enviado a evaluar: 3 de Marzo de 2011

Aceptado: 3 de Junio de 2011

\begin{abstract}
RESUMEN
El objetivo de este artículo es reconstruir el registro histórico de incendios forestales en el territorio del Valle del Guadiato y municipio de Córdoba, y analizar la influencia del fuego en la evolución del paisaje forestal. El método de investigación se basa en el manejo de fuentes documentales históricas y bibliográficas, datos estadísticos, datos paleoecológicos, y en el trabajo de campo, desde una perspectiva espacial y temporal multiescalar. Se determina la evolución del régimen de fuego en la zona de estudio, analizando asimismo la presencia del fuego como herramienta de gestión del territorio y como factor de riesgo, a lo largo del Holoceno y, en particular, de los siglos XIX y XX. A partir de estos aspectos, se profundiza en la explicación del carácter y dinámica del paisaje vegetal, la evolución de la vulnerabilidad del territorio frente al riesgo de incendios forestales, y el estudio prospectivo del comportamiento del fuego.
\end{abstract}

Palabras clave: Córdoba, incendios históricos, regímenes del fuego, paisaje forestal, gestión del territorio, Valle del Guadiato, riesgos.

\author{
Historical fire occurrence on the territory \\ Historical wildland fires in the Guadiato Valley (Cordova)
}

\begin{abstract}
This paper aims at making a reconstruction of the historical records of wildland fires in the territory of the Guadiato Valley and the municipality of Cordova, as well as at analysing the influence of fire on the evolution of forest landscape. The research method is based on the use of historical documental sources and bibliographic ones, palaeoecological data and field work, all from a multi-scale approach regarding space and time. The evolution of fire regimes in the study area is determined, also analysing the presence of fire as a tool for land management and as a risk factor, thorough the Holocene and particularly during the $19^{\text {th }}$ and $20^{\text {th }}$ centuries. Starting from these aspects, the paper goes deeper into explaining the character and dynamics of vegetal landscape, into the evolution of the territory's vulnerability to the risk of wildland fires, and to the prospective study of fire behaviour.
\end{abstract}

\footnotetext{
${ }^{1}$ Grupo de Investigación-UCM-930329-Política y Socioeconomía Forestal.
} 
Key words: Cordova, historical wildland fires, fire regimes, forest landscape, land management, Guadiato Valley, risks.

Présence historique du feu sur le territoire

Feux de forêt historiques dans le pays de la Vallée du Guadiato (Cordoue)

\section{RÉSUMÉ}

L'objective de cet article c'est la reconstruction de l'historique des incendies sur le territoire de la Vallée du Guadiato et de la commune de Cordoue, ainsi que l'analyse de l'influence des feux de forêts dans l'évolution du paysage forestier. La méthode de recherche s'appui sur l'emploie des sources documentaires historiques et bibliographiques, des données statistiques et des données paléoécologiques, et sur le travail sur le terrain, depuis une approche multi-échelle dans le temps et dans l'espace. On considère l'évolution du régime de feux dans la zone d'étude, et on étudie leur utilisation comme outil dans la gestion du territoire et comme facteur du risque, pendant l'Holocène et, en particulier, aux XIXème et XXème siècles. À partir ces aspects, on approfondit dans l'explication du caractère et de la dynamique du paysage végétal, dans l'évolution de la vulnérabilité du territoire face aux risque de feux de forêt, et dans l'étude prospective du comportement du feu.

Mots clef: Cordoue, incendies historiques, régimes du feu, paysage forestier, gestion du territoire, Vallée du Guadiato, risques.

\section{INTRODUCCIÓN}

La historia de los bosques en la cuenca mediterránea ha estado marcada por la interacción entre las condiciones y cambios climáticos, la actividad humana y la influencia de factores perturbadores como el fuego, presente sobre la faz de nuestro planeta desde el origen del mismo y con un papel fundamental en la transformación del paisaje forestal mediterráneo (PyNE, S.J., 1997. Se ha comprobado que los regímenes de fuego -entendidos como la combinación de frecuencia, severidad, intensidad, escala espacial, estacionalidad y fuente predominante de ignición- han cambiado a lo largo de las eras geológicas en función del combustible disponible, humedad y otros factores ambientales (SCHÜLE, W., 1990). Asimismo, el fuego parece ser la técnica más antigua de gestión del territorio, convirtiéndose en una práctica común para las sociedades mediterráneas del Paleolítico y Mesolítico (MAzzoleni, S. et al., 2004).

Junto con el fuego, la actividad humana y los usos del territorio han contribuido a la conformación del paisaje de los montes mediterráneos, pudiendo decirse que se trata de ecosistemas naturales y culturales, que cuentan con una fortísima componente humana de carácter histórico (Agnoletti, M., 2006; Montiel Molina, C., 2003). Incluso a corta escala, el abandono de las tierras desde mediados del siglo XX y otros cambios socio-espaciales recientes están dejando ver su influencia sobre la composición de la vegetación y sobre los regímenes de fuego: un ejemplo de esto es que el número de incendios aumenta en tierras abandonadas (TINNER, W., et al., 1998).

Hoy en día, el fuego representa uno de los mayores agentes transformadores del paisaje forestal y durante los últimos cuarenta años hemos asistido a un aumento de la frecuencia e intensidad de los incendios forestales en la región mediterránea y a la aparición de nuevos territorios de riesgo y nuevos regímenes del fuego. El regis- 
tro estadístico de este último periodo permite conocer con precisión la frecuencia y distribución de incendios. Sin embargo, no disponemos de registros continuos y comparables para valorar la presencia del fuego en etapas anteriores, lo que dificulta el estudio de los cambios provocados por el mismo sobre los ecosistemas forestales del área mediterránea (PIUssi, P., 1992).

Surge pues la necesidad de acudir a otras fuentes que complementen la información recopilada en las últimas décadas. Las fuentes históricas documentales datos sobre el registro de incendios forestales previo a la organización de la estadística. Así pues, el trabajo de archivo ofrece la posibilidad de completar la base de datos para los siglos XIX y XX, e incluso para periodos anteriores. Además, los registros paleoecológicos obtenidos gracias a testigos extraídos de sedimentos lacustres y turberas, pueden emplearse para llevar a cabo una reconstrucción paleoclimática, de la composición del paisaje vegetal, y de los regímenes del fuego y sus variaciones en los últimos milenios, enriqueciendo y completando aún más el conocimiento sobre la presencia del fuego en el territorio en tiempos pasados.

Los datos estadísticos, históricos y paleoecológicos pueden emplearse para alimentar modelos de simulación climática y de incendios con el objeto de llevar a cabo análisis prospectivos sobre las tendencias que experimentarán en el futuro dichos regímenes de fuego y el paisaje vegetal, por lo que suponen una gran aportación de cara a la futura gestión de espacios forestales y del riesgo de incendios.

\section{2. ÁMBITO DE ESTUDIO}

\subsection{SELECCIÓN DE LA ZONA DE ESTUDIO}

El registro y análisis de los incendios históricos se llevó a cabo en la provincia de Córdoba y a escala comarcal. Los criterios elegidos para seleccionar la zona de estudio se refieren a la peligrosidad y vulnerabilidad actuales frente al riesgo de incendios, ya que uno de los objetivos era investigar la relación entre el riesgo actual de incendios forestales y la presencia histórica del fuego en el territorio. Para ello, se partió del análisis de los datos estadísticos sobre incendios forestales ocurridos en la provincia de Córdoba desde el año 1968, cuando se inició el registro sistemático de estos sucesos en toda España. Se utilizaron para ello los resultados obtenidos por Doctor CABrera (1991) para el período 1968-1987, y la base de datos de la Estadística General sobre Incendios Forestales (EGIF) de la Dirección General de Medio Natural y Política Forestal del Ministerio de Medio Ambiente, Rural y Marino para el período 1989-2007.

Dicho análisis llevó a identificar las zonas de la provincia de Córdoba más afectadas por el fuego durante las últimas décadas, entre las que destaca notablemente la Comarca del Valle del Guadiato, que se perfila como una zona adecuada para plantear el estudio, por ser actualmente la más propensa y vulnerable al fuego en la provincia ${ }^{2}$.

2 En el período entre 1968 y 2007, un 46\% de la superficie total afectada por incendios en la provincia correspondió a esta zona. Sólo en el Valle del Guadiato y el Valle de los Pedroches se registró un aumento de la superficie afectada, que disminuyó en las demás comarcas y en general 
Además, dada la importancia del núcleo urbano de Córdoba, la antigüedad de los asentamientos, su proximidad al entorno serrano, con numerosas interfaces urbanoforestales -zona de transición entre el terreno urbano y el terreno forestal, donde las estructuras e instalaciones humanas entran en contacto con los espacios forestales o combustible vegetativo- (GALiANA, L., en prensa), y la gran incidencia de los incendios forestales en tiempos recientes en el municipio, se decidió incluir también este término municipal, limítrofe por el sureste con la Comarca del Valle del Guadiato, en la zona de estudio.

\subsection{LA COMARCA DEL VALLE DEL GUADIATO}

Las coordenadas geográficas de la zona de estudio son: $37^{\circ} 39^{\prime}-38^{\circ} 32^{\prime} \mathrm{N}$ y $5^{\circ}$ $35^{\prime}-4^{\circ} 15^{\prime}$ O Situada al noroeste de la provincia de Córdoba, la Comarca del Valle del Guadiato ${ }^{3}$ cuenta con una extensión total de $2.512 \mathrm{~km}^{2}$ y engloba 11 municipios: Belmez, Espiel, Fuente Obejuna, La Granjuela, Los Blázquez, Obejo, PeñarroyaPueblonuevo, Valsequillo, Villanueva del Rey, Villaharta y Villaviciosa de Córdoba. El término municipal de Córdoba, limítrofe al sur, ocupa un área de $1.245 \mathrm{~km}^{2}$. El número de habitantes de la zona de estudio en 2009 ascendía a 360.335 (31.907 habitantes de la comarca más 328.428 del término municipal de Córdoba) (SISTEMA DE INFORMACIÓN MulTiterRitorial DE ANDALucía) (figura 1).

Todo el territorio se sitúa dentro de los límites del macizo Hespérico y está formado por afloramientos de materiales, Paleozoicos y Precámbricos en su mayoría, fuertemente erosionados. El principal río de la comarca es el Guadiato, que le da nombre a la misma. Nace en el Cerro de la Caraveruela (Fuente Obejuna) y discurre encajado a lo largo de un sinclinal Paleozoico, de dirección herciniana (norte-sur), antes de verter sus aguas al Guadalquivir por su margen derecha en el término de Almodóvar del Río. La comarca presenta una configuración orográfica desigual, combinando extensas llanuras al norte con alineaciones montañosas de media altitud en el resto del territorio (Portal de la Mancomunidad del Valle del Guadiato).

en la provincia. Asimismo, se pudo observar un aumento generalizado del número de incendios, destacando nuevamente el Valle del Guadiato por el número de siniestros, más de un 36\% y 21\% del total de incendios registrados en la provincia de Córdoba para los períodos 1968-1987 y 19892007. Este aumento generalizado en el número de incendios unido a una disminución del área total afectada no puede significar otra cosa que una disminución del área afectada por incendio. Una vez más, la Comarca del Valle del Guadiato sobresale. Allí los incendios alcanzaron la mayor magnitud media en el período 1989-2007 (del que se tienen datos sobre extensión por incendio): unas 25 ha por incendio. El resto de comarcas no llegan a 5 ha por incendio (excepto el Valle de los Pedroches, 14 ha), situándose la media de la provincia por debajo de las 9 ha.

${ }^{3}$ Orden de 14 de marzo de 2003, por la que se aprueba el mapa de comarcas de Andalucía a efectos de planificación turística y deportiva. BOJA, 27 de marzo de 2003, nº 59, pp. 6428-6434. 
Figura 1. Situación de la Comarca del Valle del Guadiato y el término municipal de Córdoba y sus poblaciones dentro de la provincia.

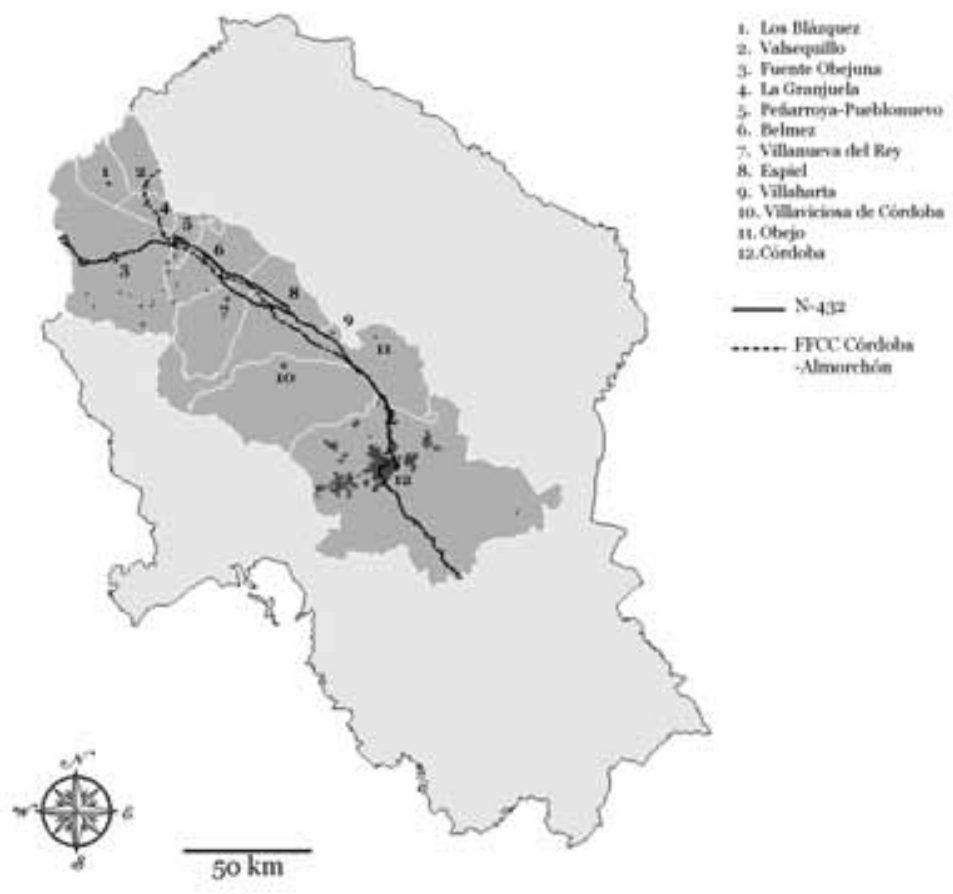

Fuente: BOJA, Orden de 14 de marzo de 2003 y Nodo de la Red de Información Ambiental, Junta de Andalucía.

El clima de la zona es mediterráneo y la situación geográfica de la comarca, al norte de la Depresión del Guadalquivir y en pleno sector central de Sierra Morena, acentúa la continentalidad. Esto resulta en una gran amplitud térmica anual y en veranos muy secos y calurosos e inviernos fríos y húmedos en los que no son extrañas las fuertes heladas. También se da la característica sequía estival e irregularidad pluvial de las zonas mediterráneas (Agencia Estatal de Meteorología). La vegetación de la zona sufre un acusado estrés hídrico, lo que hace que encontremos grandes extensiones cubiertas por especies tolerantes en cuanto a estas condiciones como son las quercíneas, tan típicas y abundantes en el ambiente mediterráneo.

El Valle del Guadiato presenta distintas unidades paisajísticas bien diferenciadas (figura 2). Al norte encontramos amplias extensiones de pastizal desarbolado y dehesas con escasos pies aislados, junto con cultivos de cereal (Solano MÁrquez Cruz, F., 1992). Recorriendo la comarca hacia el sur, el pastizal predominante va dando paso a grandes extensiones de monte bajo en y algunos encinares bien conservados. En las latitudes medias de la comarca el encinar adehesado convive con el olivar en las áreas más llanas, dando paso a encinar y monte bajo en las laderas. 
En este sector (entre Villanueva del Rey y Espiel) encontramos también manchas de pinar de repoblación, incluyendo uno de los principales núcleos de la provincia, compuesto por Pinus pinaster (Doctor CABrerA, A.M., 1991). En la zona más meridional de la Comarca del Valle del Guadiato pueden observarse formaciones de bosque mediterráneo bien conservado en Villaviciosa de Córdoba, sobre todo en la proximidad de los cursos fluviales como el del Guadiato. Al este de Villaviciosa, en Obejo, el olivar ha sustituido en gran parte al bosque mediterráneo y destacan las amplias extensiones de pinar de repoblación y manchas de eucaliptos en la Sierra de los Puntales (Solano Márquez Cruz, F., 1992).

En el término municipal de Córdoba predomina el encinar y matorral mediterráneo con manchas de quejigos en las áreas más húmedas, si bien en la franja más septentrional del término, cerca de las lindes con Obejo y Villaviciosa de Córdoba, encontramos numerosos bosques de $P$. pinaster y bosques mixtos de alcornoques y pinos, alcanzando algunos individuos portes extraordinarios. Enclavado a unos 10 $\mathrm{km}$ al norte de la ciudad se encuentra el Parque Periurbano de Los Villares, que cuenta con 485,41 hectáreas y está compuesto principalmente de pinos, encinas y matorral mediterráneo.

Restos arqueológicos datados en el Paleolítico, Neolítico y Calcolítico nos dan idea de que la comarca se ha visto sometida a transformaciones como consecuencia del uso y aprovechamiento de las sociedades humanas desde hace más de 10.000 años, existiendo evidencias de actividades mineras, ganaderas, tránsito de personas y mercancías. No se puede olvidar tampoco la importancia de la comarca como zona de tránsito entre Corduba y Emerita Augusta durante la ocupación romana, ni el carácter de marca fronteriza entre los reinos cristianos del norte y el califato o los reinos musulmanes del sur, donde parece ser que no eran raros los incendios con el fin de devastar el territorio y dificultar el avance, abastecimiento y refugio de las tropas enemigas (Solano Márquez Cruz, F., 1992). 
Figura 2. Unidades paisajísticas en la Comarca del Valle del Guadiato y el término municipal de Córdoba.
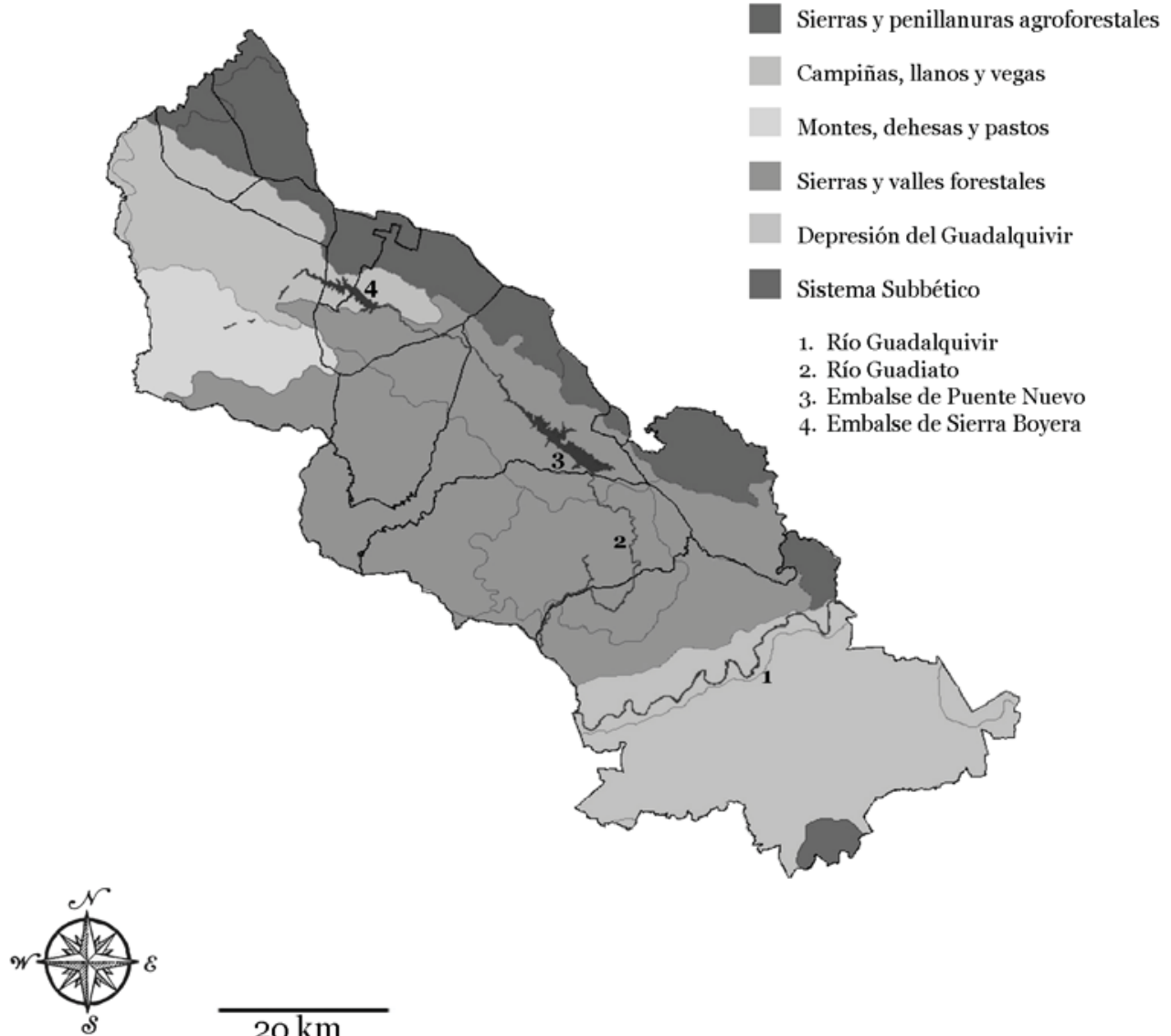

\section{$20 \mathrm{~km}$}

Fuente: Resultados obtenidos en el marco del convenio suscrito entre la Universidad Complutense de Madrid y TRAGSATEC para la caracterización de los escenarios del fuego forestal en España (20082010).

La trashumancia también dejó la impronta de su paso por el Valle del Guadiato, lo que queda reflejado en la densa red de vías pecuarias que la recorren, incluyendo parte de la Cañada Real de Merinas (que muere en Fuente Obejuna) y la Cañada Real Soriana (Consejería de Medio Ambiente, Junta de Andalucía).

La carretera N-432 que enlaza Granada con Badajoz es el principal eje de comunicación de la comarca, atravesándola de sureste a noroeste y pasando por la mayoría de los municipios que la componen. La "vía de la sierra" (como se la conocía popularmente), línea férrea que unía Córdoba con Almorchón (Badajoz) también confirió gran dinamismo a la zona desde la década de los 60 del siglo XIX, cuando se empezó 
a construir, hasta el final de la década de los 80 del siglo XX, cuando se interrumpió por completo el funcionamiento de la línea, quedando sus instalaciones abandonadas (FERROPEDIA).

La minería es una actividad económica de fuerte tradición y arraigo en la zona, existiendo al menos desde época romana, cuando se explotaban minas de metales preciosos y cobre. En tiempos más recientes, una pujante minería del carbón llevó el desarrollo a la comarca, existiendo numerosísimas concesiones y explotaciones. En los últimos años la minería del carbón ha perdido el esplendor que tuvo antaño y las canteras de áridos y gravas han reemplazado a la minería como principal actividad extractiva ${ }^{4}$.

\section{FUENTES Y MÉTODOS}

La investigación se planteó desde un enfoque multiescalar (espacial y temporalmente) a la perspectiva del fuego como agente modelador del paisaje a lo largo de la historia. Para estudiar los cambios en los regímenes de fuego así como en la estructura y composición del paisaje se llevó a cabo una primera aproximación a escala de región natural, con el Holoceno como contexto temporal. A continuación, se procedió a realizar un análisis de los datos sobre incendios históricos en la Comarca del Valle del Guadiato recogidos en las distintas fuentes documentales disponibles para el período 1820-1935, con el fin de tratar de identificar y/o establecer relaciones más precisas entre vegetación, usos del territorio y regímenes de fuego.

\subsection{REGISTROS PALEOECOLÓGICOS}

Al no haber en Sierra Morena turberas ni humedales válidos para la obtención de registros paleoecológicos, prácticamente no se han hecho estudios de polen fósil ni antracológicos que permitan llevar a cabo una reconstrucción de la historia de la vegetación en el Valle del Guadiato. Los únicos datos disponibles corresponden a un trabajo realizado sobre Sierra Madrona (DíAz FERNÁNDEZ, P.M., 1992), en una zona de estudio situada entre las provincias de Ciudad Real y Jaén, limítrofe con la parte nororiental de la provincia de Córdoba 5 . Por otro lado, se trata de información que no está datada cronológicamente y, habiéndose tomado las muestras en fondos de valle, los registros polínicos son fundamentalmente locales y vecinales, lo que limitó en gran medida el poder llevar a cabo posibles extrapolaciones de cara a realizar una aproximación a la evolución del medio forestal de la zona de estudio a lo largo del Holoceno. Para suplir esta carencia, se ha recurrido a fuentes bibliográficas y resultados sobre trabajos llevados a cabo en otras zonas de la España mediterránea.

${ }^{4}$ La información relativa a la minería en el Valle del Guadiato ha sido amablemente facilitada por el Ing. Téc. D. Antonio Granados López, Asesor Técnico de Ordenación Minera en el Servicio de Industria, Energía y Minas de la delegación en Córdoba de la Junta de Andalucía.

${ }^{5}$ Información amablemente proporcionada por el Dr. D. José Antonio López Sáez, Científico Titular del Instituto de Historia (CCHS-CSIC) y Director del Grupo de Investigación de Arqueobiología, quien también facilitó el acceso a los datos recogidos en DíAz Fernández, P.M., 1992. 


\subsection{FUENTES HISTÓRICAS Y DE ARCHIVO}

Con el objeto de identificar y datar la presencia histórica del fuego, ya sea como herramienta de gestión del territorio o como elemento renovador/perturbador del ecosistema (incendios), y caracterizar la estructura, composición y evolución del paisaje forestal en la historia reciente, se visitaron y consultaron distintas fuentes documentales históricas. La información obtenida se empleó para elaborar un listado de los incendios registrados en la Comarca del Valle del Guadiato y Córdoba entre 1820 y 1935. Las fuentes originales, en ocasiones, informaban de la extensión afectada en fanegas, por lo que se ha empleado un factor $0,644^{6}$ para mostrar los datos en hectáreas y poder así compararlos con los datos sobre incendios recientes.

En el Archivo Histórico Municipal de Córdoba se localizaron los partes de incendio de los Guardas Rurales y Forestales de 1729 a $1909^{7}$ así como distintos bandos y disposiciones específicos sobre incendios, fechados entre 1844 y $1851^{8}$. Por último, documentos de finales del siglo XVIII relativos a la villa pedánea de Santa María de Trassierra (hoy barriada en la sierra de Córdoba) aportaron información sobre la vegetación existente en los montes en la época9.

En el Archivo General de la Diputación Provincial de Córdoba ${ }^{10}$, se consultaron pedimentos de actuación concernientes a distintas fincas (cortas, podas, entresacas, etc.), de los que se extrajo cierta información sobre la cobertura vegetal existente en algunos predios de la sierra de Córdoba y la villa pedánea de Santa María de Trassierra a finales del siglo XVIII ${ }^{11}$.

Del Archivo del Ministerio de Agricultura, Pesca y Alimentación se obtuvo información ${ }^{12}$ de los partes mensuales emitidos por los ingenieros jefes de los distri-

${ }^{6}$ Consultando la sección "medidas antiguas" del Centro Español de Metrología para las provincias de Córdoba y limítrofes (Badajoz, Ciudad Real, Granada, Sevilla, Jaén, y Málaga) se pudo observarlo siguiente: en Badajoz, Ciudad Real y Granada se consideraba que la fanega tenía 64,395617 áreas; en Córdoba 61,212287 áreas; en Sevilla 59,447248; en Jaén 62,627812 áreas; y en Málaga 60,3781. Se descarta inmediatamente hacer una media, decidiéndose tomar la medida "castellana" de 64,395617 áreas por ser la más extendida y dado que la zona de estudio es limítrofe con la provincia de Badajoz, siendo por tanto más probable el empleo de la fanega castellana que el de la fanega usada en la campiña cordobesa.

${ }^{7}$ AMCO.07.11, cajas 2158 y 2159.

${ }^{8}$ AMCO.13.02.01.02, caja 1158. Documentos 1158/34.2, 1158/47, 1158/62 y 1158/85.

${ }^{9}$ AMCO, Caja T-1.

${ }^{10}$ El Dr. D. Juan Gregorio Nevado Calero, Cronista Oficial de Villaviciosa de Córdoba, presidente de la Ilustre Asociación Provincial Cordobesa de Cronistas Oficiales, y archivero en el Archivo General de la Diputación Provincial de Córdoba, colaboró en la búsqueda de documentos relevantes para la investigación, además de aportar muy valiosa información sobre los archivos locales de la zona de estudio basada en su propia experiencia investigadora.

${ }^{11}$ ES 0214 ADCO HC267.18 Plan de Montes y Plantíos, pedimentos de podas, autos sobre denuncias sobre poda y tala de árboles en tierras vinculadas.

${ }^{12}$ Estos datos, que permitieron completar la información obtenida de los partes de incendio que se conservan en el Archivo Municipal de Córdoba, fueron amablemente cedidos por cortesía del Prof. Dr. D. Eduardo Araque Jiménez, catedrático del Área de Análisis Geográfico Regional y coordinador del Grupo de Investigación Territorio y Política Regional (HUM112) en la Universidad de Jaén. 
tos forestales, correspondientes a los años $1876-1878^{13}, 1880-1882^{14}, 1883-1884^{15} \mathrm{y}$ $1890-1892^{16}$

En el Archivo General de la Administración, depositario de los datos sobre incendios forestales correspondientes a la etapa del siglo XX previa a 1967 después de que se trasladaran desde el Archivo del Ministerio de Agricultura, Pesca y Alimentación, se revisaron distintas cajas y libros del catálogo de Agricultura con el fin de contrastar y/o completar información, si bien no se encontraron datos relativos a incendios ocurridos en la provincia de Córdoba.

La consulta del fondo digitalizado de prensa histórica de la Biblioteca Nacional de España permitió recopilar noticias referentes a incendios ocurridos en la Comarca del Valle del Guadiato y el término municipal de Córdoba en el siglo XIX y principios del XX. De un total de 25.143 resultados de búsqueda, se han identificado 113 noticias referentes a incendios ocurridos en alguno de los municipios de la Comarca del Valle del Guadiato o en Córdoba ${ }^{17}$.

Una vez construida la base de datos de incendios históricos se consultó el Nuevo Atlas de Córdoba (Collazos, J.M. y Morella, A., 1998) con el objeto de localizar las fincas y montes a las que hacían referencia los partes.

\subsection{FUENTES ORALES}

Distintas comunicaciones personales planteadas a lo largo de la investigación constituyeron una importante aportación en la obtención de información para la elaboración de los resultados. La información obtenida ha respondido básicamente a consultas planteadas a expertos, cronistas locales, y personal de archivo, a través de entrevistas o encuestas abiertas.

\footnotetext{
${ }^{13}$ AMAPA, caja 261, documentos 261/1 y 261/3; caja 263, documento 263/3; caja 265, documento $265 / 1$.

14 AMAPA, caja 269, documento 269/2; caja 272, documentos 272/1, 272/2 y 272/4; caja 274, documentos 274/1 y 274/3.

15 AMAPA, caja 276, documentos 276/1, 276/3 y 276/4; caja 277, documentos 277/1, 277/2, 277/3 y $277 / 4$; caja 278 , documento $278 / 2$.

${ }^{16}$ AMAPA, caja 300, documentos 300/2 y 300/3; caja 301, documento 301/3; caja 302, documentos $302 / 1$ y $302 / 2$; caja 303 , documento $303 / 1$; caja304, documento $304 / 1$; caja 305 , documentos $305 / 1$ y $305 / 2$; caja 306 , documento $306 / 1$; caja 307 , documento $307 / 2$; caja 308 , documentos $308 / 1$ y $308 / 2$; caja 309, documento 309/1; caja 310, documentos 310/1 y $310 / 2$.

17 Se emplearon como términos de búsqueda la palabra incendio seguida del nombre de cada municipio (empleando las distintas grafías con las que podrían aparecer), y considerando también Cerro Muriano y Trassierra, dada la historia y relevancia de estas villas de la sierra cordobesa. Temporalmente se acotó entre el 1 de enero de 1683 y el 31 de diciembre de 1967, si bien los resultados obtenidos van del 16 de agosto de 1820 al 20 de junio de 1935. Las búsquedas relativas a Córdoba se limitaron al período entre el 1 de mayo y el 31 de octubre de cada año, dada la enorme cantidad de resultados que arrojaba el buscador y basándose en el hecho de que prácticamente todos los incendios documentados tuvieron lugar entre junio y septiembre. Cabe destacar asimismo la práctica inexistencia de prensa en el fondo de la Hemeroteca Digital entre 1936 y 1967.
} 


\subsection{TRABAJO DE CAMPO}

En abril de 2010 se hicieron dos salidas de reconocimiento, a Belmez y Peñarroya-Pueblonuevo, y a Espiel, Villaharta y Cerro Muriano. El desarrollo de las mismas se saldó con la visita a archivos locales, y a determinados parajes con el objeto de aproximarnos a la evaluación del carácter del paisaje. En mayo de 2010, tras documentar los incendios históricos ocurridos en la zona de estudio, se hizo un recorrido por una franja de Sierra Morena en los términos municipales de Obejo y Córdoba, en dirección E-O, comenzando en la Sierra de los Puntales (Obejo) y terminando el recorrido en el Lagar del Puerto (Córdoba), cerca de la carretera de Trassierra a Villaviciosa. Se visitaron parajes de los Puntales (Obejo), Pendolillas y La Tierna (Córdoba), la Armenta (Cerro Muriano, Obejo/Córdoba), Torreárboles (Cerro Muriano, Córdoba, donde se ubicaba una de las brigadas de vigilancia de incendios en el siglo XIX), el Parque Periurbano de los Villares, Lagar de la Cruz, sitio de Las Ermitas, Santa María de Trassierra, el Salado y el Lagar del Puerto (Córdoba). El recorrido aportó una visión global sobre las unidades paisajísticas presentes en esta franja de Sierra Morena y permitió identificar signos de incendios recientes y de épocas pasadas.

\section{RESULTADOS}

\subsection{PRESENCIA PREHISTÓRICA DEL FUEGO EN EL VALLE DEL GUADIATO}

Se ha contrastado que el Holoceno es un período de gran variabilidad ambiental en la España mediterránea (CARRIón, J.S. et al., 2010a). Se distinguen tres fases (figura 3):

Figura 3. Simplificación de las fases climáticas del Holoceno.

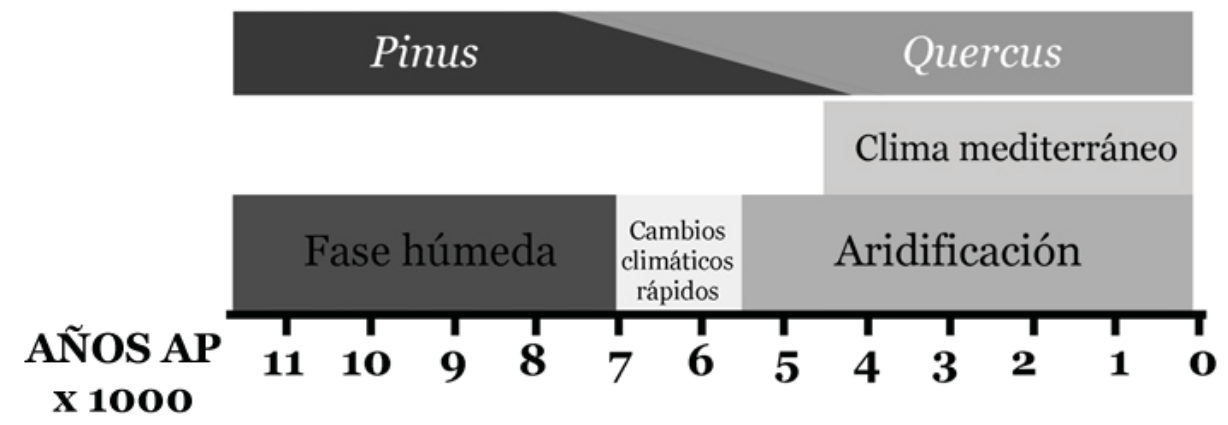

Fuente: Jalut, G. et al., 2009; Carrión, J.S. et al. (2010b); Pons, A. y Reille, M. (1988); Stevenson, A.C. (2000); MAYEWSKI, P.A. et al. (2004). 
a) Una primera (11.500-7.000 años $\left.\mathrm{AP}^{18}\right)$ mayoritariamente húmeda y favorable para el desarrollo de la cobertura vegetal (JALUT, G. et al., 2009), en la que bosques de Pinus dominaron el paisaje glacial y resistieron la invasión de otras especies hasta aproximadamente 5.900 años AP, si bien especies del género Quercus y otros árboles de climas templados ya aparecieron en el sur de Iberia algunos miles de años antes (CARrión, J.S. et al., 2010b). Algunas secuencias de polen incluso muestran predominio de Quercus ya desde el Holoceno temprano (Pons, A. y ReILle, M., 1998), y otras sin embargo apuntan que especies del género Pinus continuaron dominando hasta el Holoceno intermedio (CARRIÓN, J.S. y VAN GEEL, B., 1999), o incluso hasta etapas posteriores (Stevenson, A.C., 2000).

b) La segunda fase (7.000-5.500 años AP) estuvo marcada por un progresivo descenso de la insolación a altas latitudes en el hemisferio norte, lo que se considera una posible causa de los rápidos cambios climáticos registrados en torno a 6.000-5.000 y 3.500-2.500 años AP (MAYEWSKI, P.A. et al., 2004). Con respecto a la cobertura vegetal, esta fase representa el óptimo mesofítico y el mínimo xerofítico, así como el periodo de menor actividad del fuego en la Península Ibérica. (CARRIón, J.S. et al., 2007).

c) La tercera etapa (5.500 años AP - hoy en día) está marcada por una creciente aridificación demostrada por datos polínicos, hidrológicos y marinos bien correlacionados (Fontugne, M. et al., 1994; Schilman, B. et al., 2001). Los bosques caducifolios de hoja ancha entraron en declive, favoreciéndose la expansión de taxones esclerófilos de hoja perenne (MAYEWSKI, P.A. et al., 2004). Dentro de esta tercera fase, el período comprendido entre 4.500-4.000 años AP supuso en el Mediterráneo occidental el comienzo de la evolución hacia un clima completamente Mediterráneo (DorAdo VALiÑo, M. et al., 1999; MAYewsKi, P.A. et al., 2004). Se ha registrado asimismo un período árido entre 3.500-2.500 años AP, seguido del Período Húmedo Íbero-Romano (2.500-1.600 años AP, o bien 500 a.C - 400 d.C), y otra fase seca entre $1.300-750$ años AP (que se corresponde con la Anomalía Climática Medieval, 800-1300 d.C) (MAYEWSKI, P.A. et al., 2004; PÉrez, F.F. y Boscolo, R., 2010); tras esta última, vino la Pequeña Edad del Hielo (1300-1850 d.C) y desde entonces el clima se ha ido haciendo más cálido hasta alcanzar los valores que conocemos en la actualidad.

En lo que respecta a la prehistoria del fuego, los regímenes de fuego en Europa estaban principalmente determinados por causas naturales hasta que el ser humano domesticó el fuego (PyNe, S.J, 1997). El origen del uso del fuego como herramienta de gestión se ha datado a mediados del Paleolítico (Müller-KARPE, H., 1992) y, aunque ya se trataba de una práctica común para las sociedades mediterráneas del Mesolítico y Neolítico (MAzzoleni, S. et al., 2004), poco se conoce sobre las prácticas de uso del fuego antes de estos períodos, lo que hace que el límite entre fuego antrópico y fuego natural durante este período sea muy difuso (SeVilla Martínez, F, 2008; Carrión, J.S., 2010b; PYNE, S.J, 1997).

El estudio de diversos testigos extraídos de sedimentos lacustres y turberas en toda Europa ha permitido constatar una menor actividad del fuego durante las etapas temprana e intermedia del Holoceno (11.000 a circa 3.000 años AP). Desde entonces, la

18 "años AP" hace referencia a "años antes del presente". 
combustión de biomasa ha ido aumentando, destacando sobre todo el crecimiento experimentado en los últimos 1.000 años (CARCAILlET, C. et al., 2002).

En el caso particular de la zona de estudio, existen evidencias arqueológicas que prueban que la Comarca del Valle del Guadiato ha estado poblada desde el Paleolítico (Solano MÁrquez Cruz, F., 1992), por lo que se puede afirmar que ha estado sometida a transformaciones como consecuencia de los usos y aprovechamientos humanos desde hace más de 10.000 años

Tomando como referencia los datos recogidos en el trabajo de Díaz Fernández sobre Sierra Madrona (1992), anteriormente mencionado, y considerando únicamente los resultados relativos a los testigos extraídos en los sitios del Valle de los Caballeros del Escorial y Navalmanzano-Quintana (Fuencaliente, Ciudad Real) por ser los más próximos a nuestra zona de estudio, pudimos identificar una serie de hechos con carácter general. No se muestran evidencias de cambios climáticos (DíAz Fernández, P.M., 1992), por lo que se podría pensar que las secuencias se encuentran dentro del período desde que se asentó definitivamente el clima mediterráneo (4.500-4.000 años AP, como ya se ha visto). Además, ambos registros muestran un aumento de los niveles de concentración polen arbóreo desde los materiales más antiguos a los más superficiales, simultáneo a un descenso del polen de especies arbustivas y herbáceas, lo que es indicador de la progresión general del bosque (DíAz FERNÁndez, P.M., 1992).

La mayor abundancia de compuestas en las bases de las secuencias indica condiciones de aridez local superior a la actual (DíAz Fernández, P.M., 1992), posiblemente síncrona con la Anomalía Climática Medieval (800-1300 AD). Posterior a este pico de compuestas, se observan máximos de Erica y Cistus y Asphodelus, así como un máximo en la curva de carbón, indicadores de alta actividad del fuego (CARRIÓN, J.S. y VAN Geel, B., 1999; CARrión, J.S., 2002; LóPez-SÁez, J.A. et al., 1998; CARrión, J.S. et al., 2010b). Y en los materiales más recientes, se observa un descenso de la presencia de carbón, signo de disminución en la actividad del fuego en la zona.

El predominio de los Quercus queda patente en ambas secuencias, y la representación de especies de Pinus es escasa, aunque aumenta en los materiales más recientes. Este hecho es seguramente indicador de las repoblaciones efectuadas en la segunda mitad del siglo XX (DíAz Fernández, P.M., 1992), a la vez que una muestra más de la cautela con la que han de considerarse estos datos, ya que conocemos por fuentes históricas anteriormente mencionadas que la presencia de pinos, al menos en la franja de la sierra que se extiende al norte de la ciudad de Córdoba, no era escasa sino más bien predominante, como lo es hoy en día en muchas localizaciones en el entorno de Trassierra o Cerro Muriano.

\subsection{USO HISTÓRICO DEL FUEGO EN LA GESTIÓN DEL TERRITORIO EN EL VALLE DEL GUADIATO}

Los montes son sistemas históricos, tanto los más humanizados como aquellos medios alterados, y eventos sucedidos en el pasado condicionan procesos en el presente (Sevilla Martínez, F., 2008). Muchas de las actividades desarrolladas por el 
ser humano en la Comarca del Valle del Guadiato, como el pastoreo, la agricultura, carboneo, estuvieron ligadas al uso del fuego. El análisis de estas actividades puede darnos una idea más o menos precisa sobre el uso histórico del fuego.

Una de las unidades paisajísticas más características de este sector de Sierra Morena es la dehesa (Solano MÁrquez Cruz, F., 1992). Se trata de ecosistemas antropogénicos que aparecen tras la deforestación, mediante tala, introducción del ganado o uso del fuego, del bosque original, provocando la desaparición del estrato arbustivo, la aparición de pastos y disminuyendo el número de pies arbóreos, con lo que se genera un "bosque-parque" que permite pacer al ganado (LópEZ-SÁEZ, J.A., 2007; Sevilla Martínez, F., 2008). La abundancia de dehesas y bosques adehesados en la comarca es indicadora por tanto de una deforestación pretérita que, sin duda, contó con el fuego como una de las herramientas empleadas.

Pero el pastoreo en el Valle del Guadiato no se limitaba a las grandes extensiones de monte adehesado: la densa red de vías pecuarias existente en la zona nos lleva a pensar que el pastoreo trashumante, y por ende el fuego como herramienta de mantenimiento y/o apertura de pastos, tuvo gran importancia en la región. Además, se debe tener en cuenta la degradación del bosque por los animales: el desplazamiento del rebaño ya supone una alteración en sí y el aumento de la carga ganadera a partir del siglo XIII provoca un tránsito más frecuente, que se traduce en sobrepastoreo y mayor degradación de la vegetación, comprometiendo la regeneración de árboles y arbustos y haciéndolos más vulnerables al fuego (CLÉMENT, V., 2002).

El uso del fuego estuvo asimismo fuertemente ligado a esta agricultura complementaria a la ganadería. La deforestación era una práctica común para abrir espacios en los que poder introducir cultivos y el fuego era una herramienta eficaz y más rápida y cómoda que el hacha. Sabemos que la roza era una técnica común en la zona ya que existen documentos que así lo atestiguan. Así, por ejemplo, en el Archivo Histórico del Ayuntamiento de Espiel se conservan cuentas de propios desde el año 1.606 , en las que se incluyen las sentencias de roza ${ }^{19}$.

Se podría afirmar que el uso del fuego como herramienta de gestión del territorio era un hecho generalizado en la zona. A pesar de que no se han localizado en los archivos locales de la Comarca del Valle del Guadiato documentos que atestigüen estas prácticas, algunos bandos dictados por distintos alcaldes decimonónicos de la ciudad de Córdoba, en los que regulan el uso del fuego durante la época estival, así lo corroboran ${ }^{20}$.

\footnotetext{
${ }^{19}$ Los agricultores debían abonar anualmente una cantidad para poder llevar a cabo la roza de las tierras que laboraban. Archivo Histórico del Ayuntamiento de Espiel, cajas 7 y 8, información amablemente facilitada por el Dr. D. Juan Gregorio Nevado Calero.

${ }^{20}$ AMCO, caja 1158, documento 1158/34.2, bando fechado el 19 de junio de 1844, en el que el alcalde José María Conde dispone que "ninguna persona pueda hacer picón, encender fuegos descubiertos ni clase alguna de ellos en los campos o eras hasta el 8 de setiembre". AMCO, caja 1158, documento $1158 / 47$, Luis Bertrán de Lis, alcalde en 1847, renueva un bando dictado el año anterior y elabora uno nuevo, fechado el 12 de julio, por el que, entre otras disposiciones, establece en su artículo $1^{\circ}$ que "Sin especial licencia de la autoridad a nadie será permitido prender fuego a sus rastrojos, pastos ni montes hasta el día ocho de setiembre". AMCO, caja 1158, documento 1158/85, Antonio García del Cid, dicta un bando el 15 de junio de 1853, prohibiendo también hacer fuego durante el verano.
} 
Pero el uso del fuego en la Comarca del Valle del Guadiato no se daba únicamente con fines deforestadores. Parece ser que ya desde el siglo XIX se empleaba, con mayor o menor frecuencia, el fuego técnico en la extinción de incendios. Como prueba de ello, se han podido documentar al menos dos casos en los que los guardas forestales emplearon u ordenaron el uso del contrafuego ${ }^{21}$.

\subsection{INCENDIOS HISTÓRICOS}

Las fuentes documentales permitieron identificar más de 500 incendios en el periodo 1820-1935. Dos hechos son particularmente destacables en cuanto al número de siniestros registrados. Por un lado, en el período estudiado tuvieron lugar una cantidad notablemente inferior de incendios a los valores recientes; por otra parte, no se puede constatar una tendencia general creciente ni decreciente. Entre 1865 y 1874 se da un pico en el número de incendios (120 en esos 10 años), bajando éste a la mitad de esos valores en la década siguiente (53) para experimentar a continuación un ascenso significativo, registrándose 163 incendios entre 1885 y 1894 . Desde el comienzo del siglo XX, salvo entre 1905 y 1909, cuando se tuvieron lugar 45 incendios documentados, el número de siniestros es realmente bajo (figura 4).

Figura 4. Evolución del número de incendios forestales en la Comarca del Valle del Guadiato y el término municipal de Córdoba entre 1820-1935 y 1989-2007 mostrada en quinquenios.

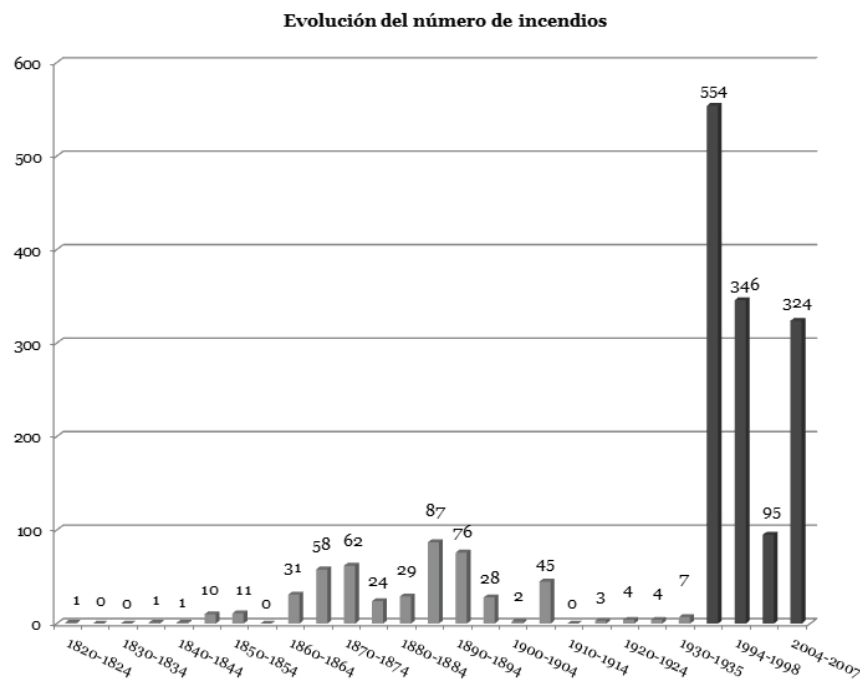

Fuente: AMCO, AMAPA y prensa histórica; Base de datos de la Estadística General de Incendios Forestales.

${ }^{21}$ AMCO, caja 2158, el parte sobre el incendio ocurrido el 2 de septiembre de 1866 en La Conejera, Córdoba, recoge cómo el guarda ordena hacer un contrafuego. AMCO, caja 2159, el parte correspondiente al incendio ocurrido el 28 de agosto de 1908 en la zona de Trassierra (Córdoba) recoge el informe del guarda, que intentó extinguir el incendio declarado mediante el uso del contrafuego en varias ocasiones. 
La superficie afectada por incendios forestales durante el período estudiado se situó en general por debajo de los valores actuales, habiendo momentos puntuales en los que la superficie afectada se disparó, destacando el espectacular aumento entre 1885 y 1894, período en el que se situó cerca de los valores recientes (más de 10.000 ha). También se ha constatado una acusada irregularidad. Los últimos 30 años del siglo XIX muestran la tendencia de crecimiento más acusada, pasando de 720 ha ardidas al comienzo de la década de los 70 de dicho siglo, a las más de 6.500 ha que ardieron en los últimos cinco años de la década de los 90. Tras ese espectacular aumento, la cifra se redujo a valores 10 veces inferiores, unas 670 ha, en los primeros años del nuevo siglo (figura 5).

Figura 5. Evolución del la superficie afectada por incendios forestales en la Comarca del Valle del Guadiato y el término municipal de Córdoba entre 1820-1935 y 1989-2007 mostrada en quinquenios.

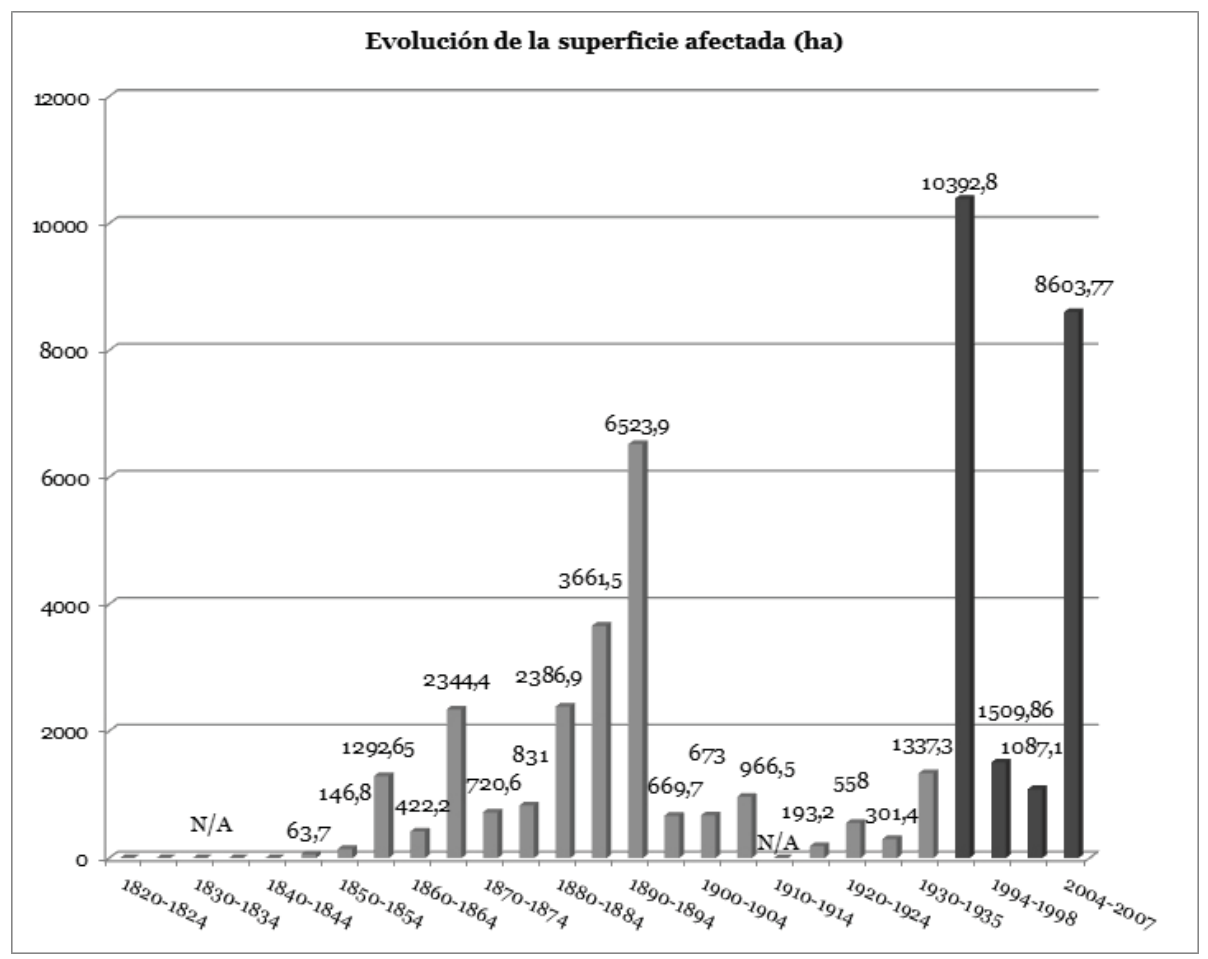

Fuente: AMCO, AMAPA y prensa histórica; Base de datos de la Estadística General de Incendios Forestales.

Tampoco se ha constatado una tendencia general creciente o decreciente en cuanto a superficie media afectada por incendio, si bien entre 1900 y 1904 se dispara la cifra, siendo también bastante elevada entre 1930 y 1935. De 1820 a 2007 ha aumentado enormemente el número de incendios registrados, si bien cada uno de éstos afecta, 
por término medio, a una extensión menor como consecuencia lógica del aumento de efectivos y eficacia del sistema de detección y extinción a partir de los años 70 del siglo XX (figura 6).

Figura 6. Evolución de la superficie media afectada por incendio en la Comarca del Valle del Guadiato y el término municipal de Córdoba entre 1820-1935 y 1989-2007 mostrada en quinquenios.

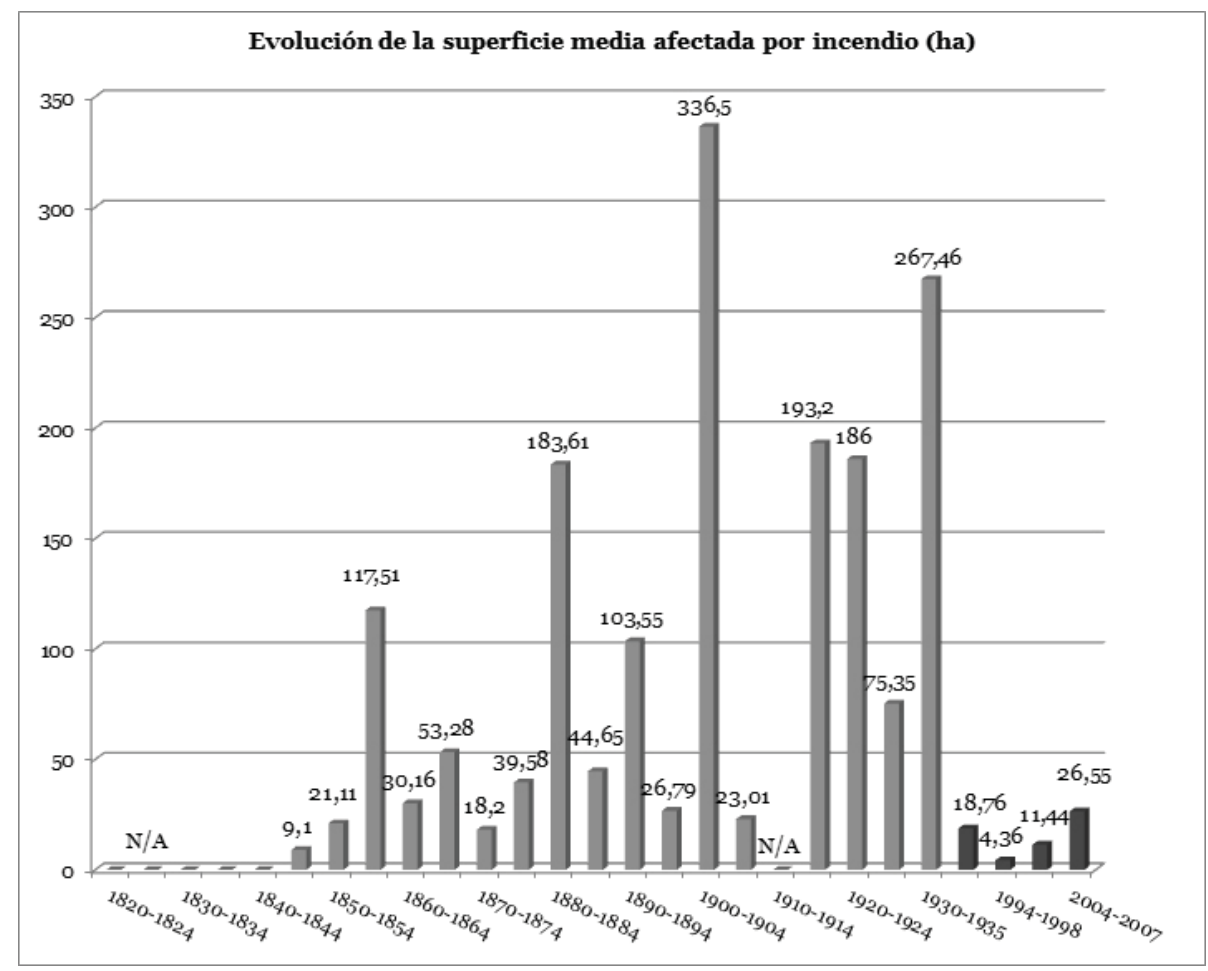

Fuente: AMCO, AMAPA y prensa histórica; Base de datos de la Estadística General de Incendios Forestales.

Se puede resumir pues, que el número de incendios en ocurridos en el Valle del Guadiato y Córdoba durante el siglo XIX y el primer tercio del XX fue sensiblemente menor a los valores actuales. La superficie afectada, aunque también menor, no lo es en la misma proporción, lo que queda reflejado en la extensión media que alcanzaba cada episodio, sensiblemente mayor que la extensión media afectada por cada incendio forestal en los últimos años. Los datos cuantitativos de superficie total y media afectada por incendios forestales y de número de incendios han de considerarse con cautela ya que no podemos tener la certeza de que los incendios recogidos constituyen una relación más o menos completa y precisa. Aún así, permiten hacer una comparación y dan asimismo una idea sobre la incidencia de los incendios forestales en la época. En cuanto a la distribución temporal intra-anual, el análisis de los datos obtenidos nos permite afirmar que la práctica totalidad de los incendios documenta- 
dos tuvieron lugar de junio a septiembre, ambos inclusive, distribución característica en áreas de clima mediterráneo.

De entre los incendios documentados entre 1820 y 1935, se han podido localizar 436. De éstos, una abrumadora mayoría de los incendios registrados (más del 95\%) ocurrió en predios pertenecientes a los actuales términos municipales de Córdoba y Obejo, formando una franja en dirección suroeste-noreste a lo largo de la Sierra. Este patrón de distribución salta a la vista por su carácter marcadamente localizado a diferencia del patrón que presentan los incendios recientes (352 eventos entre 1989 y 2007), mucho más disperso (figura 7) ${ }^{22}$.

Figura 7. Distribución espacial de los incendios forestales registrados en el Valle del Guadiato y Córdoba entre $1820-1935$ y $1989-2007$.

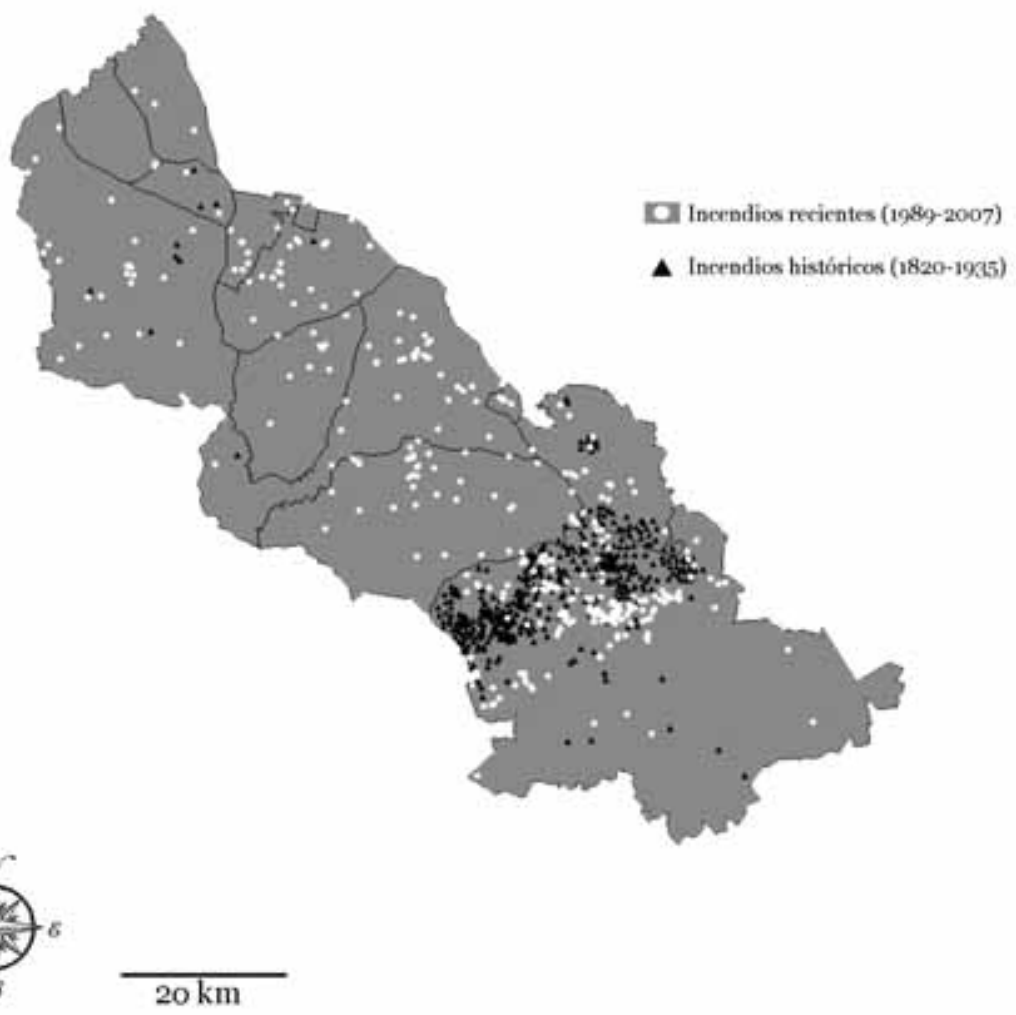

Fuente: AMCO, AMAPA y prensa histórica; Base de datos de la Estadística General de Incendios Forestales.

${ }^{22}$ La distribución espacial de los incendios históricos debe considerarse como una aproximación, dada la dificultad para localizar con precisión los distintos siniestros registrados y debido a que no se encontró documentación en archivos locales de la comarca y los partes de incendio conservados en el Archivo Municipal de Córdoba referentes a otros términos son escasos. 
En cuanto a la causalidad de los incendios históricos, éstos se pueden clasificar en tres grandes grupos: accidentales (chispas del tren, de los antiguos tendidos eléctricos, etc.), por negligencias (quema de rastrojo, restos de hogueras, colillas, caza, maniobras militares), o intencionales (fuegos pastorales, roza y apertura de espacios agrícolas, extracción "encubierta” de maderas, venganzas personales) (ARAQUE JIMÉNEZ, E. et al., 2000).

Por lo que respecta a posibles incendios relacionados con el ferrocarril, atrae nuestra atención la línea Córdoba-Almorchón (Badajoz), si bien parece ser que en la provincia de Córdoba, a diferencia de lo que ocurrió en los bosques de Pinus de la Sierra Morena jiennense, no existió relación directa entre la demanda de madera para traviesas y los incendios ${ }^{23}$. No obstante, se pudieron dar abusos en la corta de árboles tras incendios ocurridos en bosques de pinos $^{24}$. Existen, además, casos documentados en los que las chispas desprendidas por el ferrocarril al subir las cuestas de Sierra Morena, o los carbones encendidos que caen del tren provocan incendios, si bien se trata de episodios aislados. En la zona y período estudiados, sólo se ha encontrado una referencia a esta causa de incendio ${ }^{25}$.

La minería, actividad económica de gran importancia en la Comarca del Valle del Guadiato, podría haber propiciado directamente la aparición de incendios ya que la madera flameada podía emplearse para las entibaciones de las galerías y, por supuesto, para la fundición de minerales ${ }^{26}$ e industria auxiliar (MÉTAILlE, J.P., 1992). Cabe recordar que se han hallado restos arqueológicos de útiles mineros de época romana ${ }^{27}$ y aún hoy en día continua habiendo explotaciones en activo. No obstante, no se han hallado pruebas documentales que establezcan una relación entre la fuerte presencia minera y los incendios forestales históricos en la zona. Un estudio más en detalle de las subastas de madera (ARAQUE JiMÉNEZ, E., 1999), recogidas en el Boletín Oficial de la Provincia, podría arrojar luz sobre este hecho.

Los incendios desencadenados por prácticas inadecuadas de uso del fuego y por causas accidentales estarían a la orden del día. Algunos ejemplos de ello quedan ilustrados en la prensa histórica ${ }^{28}$ o en los partes de incendio. Asimismo, la existencia de normativa prohibiendo durante la época estival la quema de rastrojo, el uso de fósforos en el campo y otras actividades en las que el fuego estuviera implicado (comentada más arriba), no sólo da una idea de que se trataba de prácticas habituales sino también de que el resultado era en muchas ocasiones la declaración de un incendio.

El bosque proporcionaba numerosos recursos a muchos de los habitantes del medio rural (madera, resina, hongos, plantas aromáticas y medicinales, frutos, etc.), por

\footnotetext{
${ }^{23}$ Información amablemente facilitada por el Prof. Dr. D. Eduardo Araque.

${ }^{24}$ AMAPA, caja 276, 276-1/693 y 276-3/721; caja 277, 277-1/763, 277-2/789 y 277-3/799; caja 278, 278-2/826, en relación al incendio ocurrido en Agosto de 1881 en el Caño de la Escaravita, Trassierra.

${ }_{25}$ AMCO.07.11, caja 2159, el 14 de agosto de 1893, 1 fanega de olivar con 28 pies ardió en Los Pradillos (Córdoba) al desprenderse carbón encendido del tren.

${ }^{26}$ Información amablemente facilitada por el Prof. Dr. D. Eduardo Araque.

${ }^{27}$ Como los que pueden contemplarse en el Museo Histórico y del Territorio Minero de Belmez.

${ }^{28}$ El Día (Madrid, 1881), viernes 26 de junio de 1894, página 3: “El día 26 del actual se declaró un violento incendio en la finca llamada Puntales, en el término de Espiel (Córdoba), quemándose 25 fanegas de pastos (...). El incendio se produjo, según parece, al arrojar José Márquez Castro una punta de cigarro encendida.".
} 
lo que parece absurdo pensar que alguien amenace consciente e intencionadamente su medio de subsistencia y (CLÉMENT, V., 2002). Aquellos cuyas actividades económicas dependieran de los recursos del bosque se verían perjudicados los primeros y, además, desde mediados del siglo XX, podrían verse forzados a abandonar sus hogares y emigrar a núcleos industriales (ARAQue JiMÉnEZ, E, 1999).

Sin embargo, esto no quiere decir que no hubiera quienes se beneficiaran de los posibles incendios. Por un lado, ganaderos y agricultores empleaban el fuego para transformar bosques en dehesas, pastizales o tierras de labor, actividad que, como ya hemos visto, no era infrecuente. Asimismo, algunos partes de incendio de los guardas de las partidas rurales de Córdoba, ante la escasez de trabajadores, informan de cómo bajaban a las poblaciones con el objeto de reclutar piconeros que colaborasen en las tareas de extinción a cambio de una retribución económica. Basándonos en este hecho, podríamos concluir que este colectivo también obtendría un beneficio de los incendios forestales.

Finalmente, en la prensa histórica encontramos ejemplos de casos en los que se atribuye la autoría del incendio a un piconero, si bien no especifica si se trata de una negligencia o una acción dolosa ${ }^{29}$. En otras ocasiones, si bien coinciden en la intencionalidad, distintas fuentes difieren a la hora de describir cómo se originó un mismo evento $^{30}$, por lo que determinar la autoría de los incendios es difícil, salvo en los pocos casos en los que se identifica al culpable por haber sido sorprendido in fraganti o tras un proceso judicial ${ }^{31}$. Es frecuente encontrar, adjuntas a los partes de incendio, citaciones judiciales a los guardas para que éstos declaren en los procesos abiertos para esclarecer la autoría de los incendios.

\section{DISCUSIÓN}

\subsection{CAMBIOS EN LOS REGÍMENES DEL FUEGO, RELACIÓN CON LA EVO- LUCIÓN CLIMÁTICA Y DEL CONTEXTO SOCIOECONÓMICO}

Atendiendo a los datos obtenidos sobre incendios históricos y a la comparación hecha con los datos sobre incendios recientes, podemos afirmar que ha habido un cambio en el régimen del fuego predominante en la zona de estudio a lo largo del período cubierto por la investigación. Como ya hemos visto, la superficie afectada por incendios forestales es, en general, sensiblemente mayor en las últimas décadas, al igual que el

${ }^{29}$ El Clamor Público (Madrid, 1844), 15 de octubre de 1862, página 3: "Hace dos o tres días ha tenido lugar un incendio cerca de Trassierra, quemándose como unas siete fanegas pobladas de pinar. Parece que se instruye la correspondiente causa por haber indicios de que el fuego ha sido ocasionado por un piconero (...).".

${ }^{30}$ Entre otros: La Correspondencia de España, 7 de agosto de 1893: “(...) Aumentan las sospechas de que los incendios sean intencionales, pues empieza al mismo tiempo por diversos puntos (...).”; La Iberia (Madrid, 1854), 7 de agosto de 1893, página 3: “(...) Se ignora el origen del incendio, que se cree casual por haber comenzado en la linde de un camino"; Diario Oficial de Avisos de Madrid, 7 de agosto de 1893, página 2: “(...) Dícese que el fuego ha sido intencionado (...)”.

${ }^{31}$ El Liberal (Madrid, 1879), 25 de agosto de 1882, página 2: "En Fuente Ovejuna ha sido detenido Antonio Cabezas Rodríguez, autor del incendio ocurrido en la dehesa del Alamillo.”. 
número de incendios registrados. Esto resulta obviamente en una menor superficie media afectada por incendio. El aumento en los últimos años de la ocurrencia y magnitud de los incendios forestales es además signo de aumento de la peligrosidad.

La irregularidad interanual observada puede obedecer a varios factores. Uno de ellos es la meteorología, expresión a su vez del clima. En tanto que clima y meteorología tienen una amplia y directa influencia sobre el desarrollo de la vegetación (combustible), no podemos obviar la relación entre éstas y los regímenes del fuego. Hay que tener en cuenta, entre otras cuestiones, que la mayor incidencia de incendios forestales no se debe a la ocurrencia de un período seco en sí, sino a la alternancia entre períodos secos y húmedos (Pyne, S.J., 1997). Claro ejemplo de ello es la sequía experimentada en España durante la década de los 90, cuando se dispararon los incendios al concurrir las condiciones adecuadas para la ignición y la disponibilidad de combustible tras un período anterior en el que la vegetación había experimentado un fuerte desarrollo.

Por otra parte, no se pueden despreciar los efectos directos e indirectos de los distintos usos y aprovechamientos humanos del territorio ya desde el Paleolítico, aunque de manera más notable desde el Neolítico. El registro histórico de incendios confirma la influencia de las dinámicas territoriales sobre los regímenes del fuego a lo largo de la historia al estar las causas de los incendios documentados ligadas en mayor o menor medida a las actividades humanas desarrolladas en el Valle del Guadiato y en Córdoba. Asimismo, la evolución del contexto socioeconómico, y de las propias actividades que han tenido y tienen lugar en la zona (nuevas demandas sociales, nuevos usos del territorio forestal) guarda relación con la evolución no sólo en la causalidad sino también en la frecuencia de los incendios.

El que haya un número mayor de incendios respondería al aumento de las fuentes de ignición de origen antrópico (Sevilla Martínez, F., 2008). No obstante, la eficacia de los avanzados medios de detección y extinción disponibles en la actualidad hace que la mayoría de estos incendios no alcancen una gran extensión, aunque también ha aumentado sensiblemente el número de grandes incendios forestales o GIF (de extensión superior a $500 \mathrm{ha}$ ) en las últimas décadas, incendios que, tras escapar al control de los medios de extinción alcanzan una magnitud desproporcionada, muchísimo mayor que la alcanzada por los incendios históricos. Esto se debe, entre otros motivos, a que la rotación de cultivos y el mosaico paisajístico existente en el sistema agrario tradicional actuaban como cortafuegos, al igual que la extracción de leñas y los usos ganaderos, ya que limpiaban el bosque de biomasa (combustible). Si bien existía el uso del fuego en las labores tradicionales, también hay que tener en cuenta que estas prácticas eran llevadas a cabo por manos expertas, escapando el fuego a su control en raras ocasiones (ArAque JimÉneZ, E., 1999).

\subsection{EL FUEGO COMO AGENTE MODELADOR DEL PAISAJE}

En cuanto a los distintos regímenes de fuego que se han sucedido a lo largo del tiempo, éstos han contribuido a cambiar la estructura y composición de los ecosistemas forestales. Además de las consecuencias a corto plazo, como puede ser la des- 
trucción directa de la cobertura vegetal, el fuego puede tener efectos a largo plazo debido a las diferencias fisiológicas entre especies vegetales. Cada especie posee un conjunto de características vitales que les permite o no su instalación o expansión tras una renovación (tradicionalmente llamada "perturbación"), como son los incendios. Los pinos, por ejemplo, son buenos colonizadores tras una deforestación y proliferan bien en condiciones de incendios de fuerte afección pero baja frecuencia, y en general en períodos en los que se alterne deforestación con recuperación boscosa. Sin embargo, un uso frecuente del fuego hace que desaparezcan, pudiendo limitar su presencia durante siglos, y sólo algunos Quercus persisten, gracias a su gran resiliencia (SEVILLA Martínez, F., 2008).

Como ejemplo, en la zona en torno a la barriada de Santa María de Trassierra, antigua Villa Pedánea de Córdoba, encontramos gran abundancia de pinos, sobre todo de la especie P.pinaster, mezclados con alcornoques, encinas y otras especies. Su distribución irregular y el porte de muchos ejemplares nos llevan a descartar que se trate de pinares de repoblación. Sin embargo, a medida que nos alejamos de esta antigua villa, encontramos formaciones de matorral y monte bajo. Basándonos en fuentes históricas anteriormente mencionadas, que nos dan a entender que el pinar no sólo no era escaso en la zona, sino incluso predominante, podemos pensar que los frecuentes incendios registrados en la zona (El Hornillo, El Rosal, Caño de la Escaravita, Lagar de Don Sancho, La Aguardentera, etc.) contribuyeron a conformar este paisaje (figura 8).

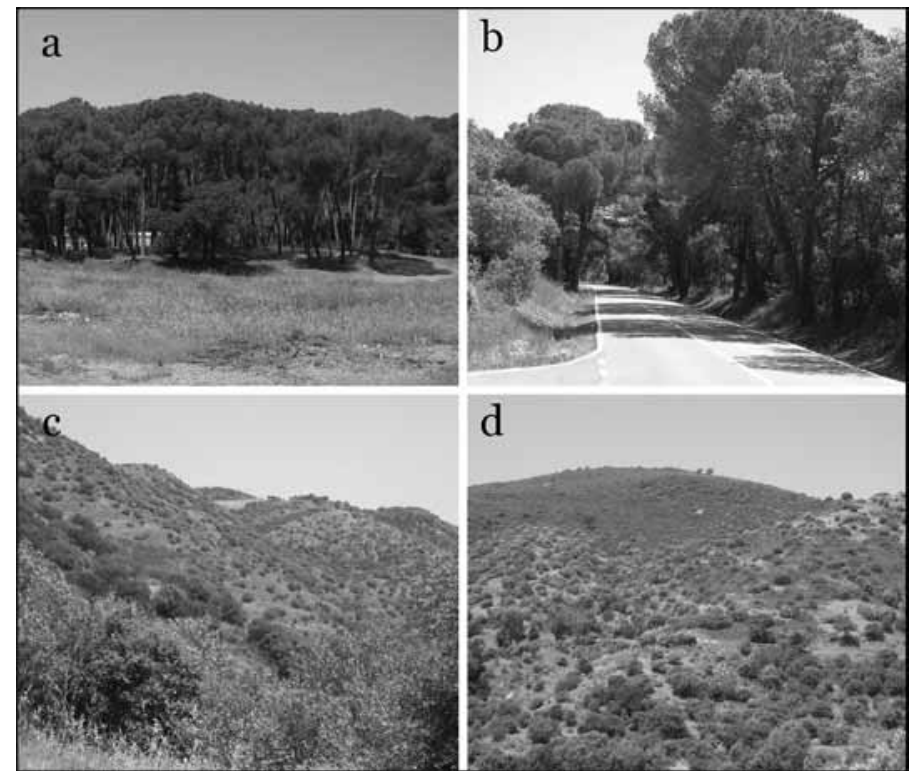

Figura 8. a) Pinar cerca del Lagar del Puerto, Sta. $M^{a}$ de Trassierra, Córdoba. b) Pinos flanqueando la carretera de Trassierra, Córdoba. c) Vista de El Hornillo, cerca de Sta. Ma de Trassierra, Córdoba. d) Vista del Lagar del Rosal, cerca de Sta. Ma de Trassierra, Córdoba. Autor de las fotografías: Lázaro Entrenas Martínez. 
La misma dinámica podría haberse dado al este de esta zona, en torno a Los Villares, lo que hoy es el Parque Periurbano homónimo, cubierto por pinar de repoblación y algunas encinas dispersas, y Campo Bajo, que contrasta con Cerro Muriano, donde también abundan los pinos; continuando hacia el este, se encuentra la zona conocida como La Armenta, también muy afectada por los incendios forestales en el siglo XIX y principios del XX, situada entre los términos de Córdoba y Obejo (figura 9).

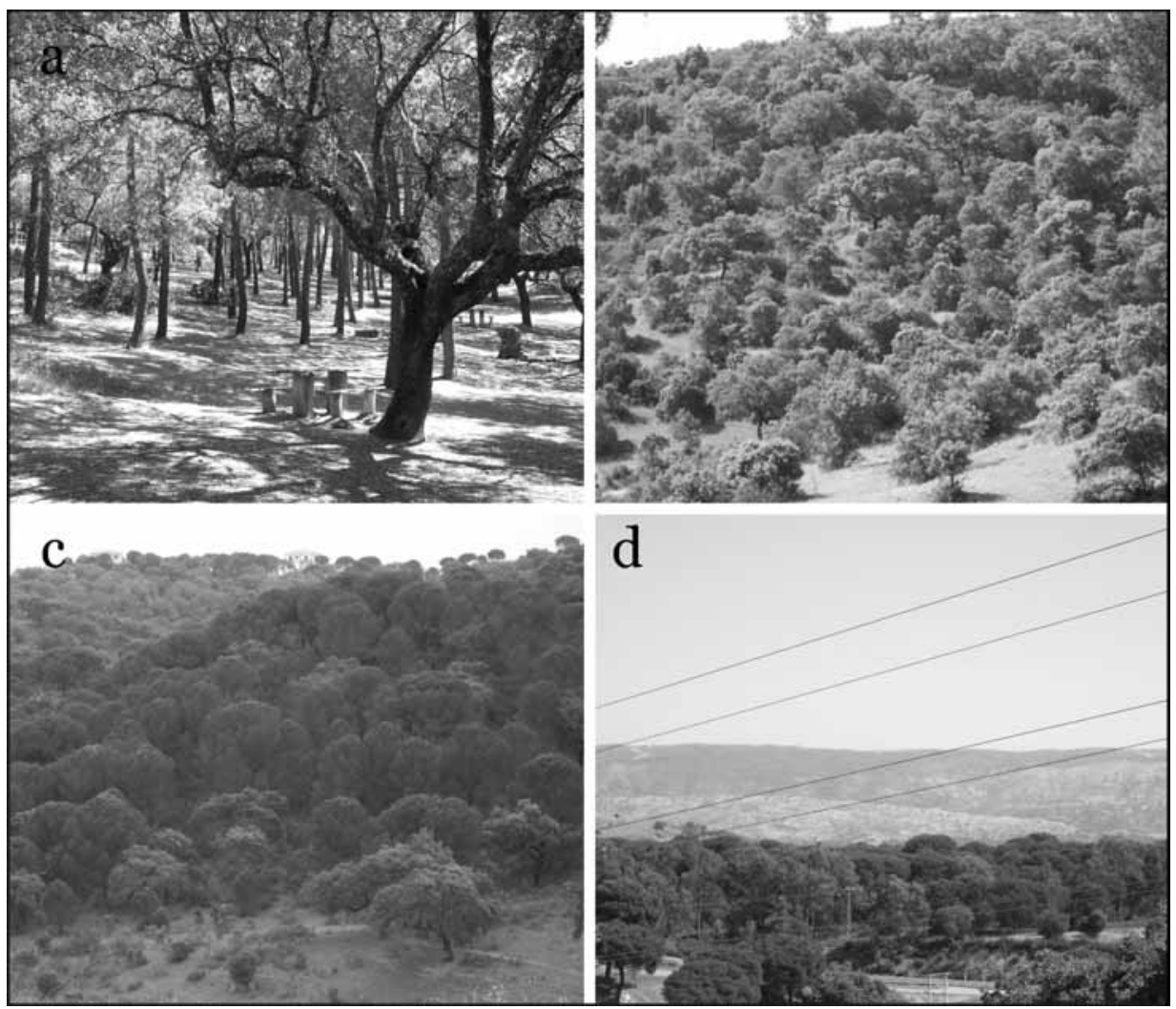

Figura 9. a) Encina y pinar de repoblación, Parque Periurbano de Los Villares, Córdoba. b) Alcornoques y encinas en Campo Bajo, Cerro Muriano, Córdoba. c) Pinar con Quercus en Cerro Muriano, Córdoba. d) Vista de La Armenta, en segundo plano, desde Torreárboles; en primer plano, pinar con Quercus en Cerro Muriano, Córdoba. Autor de las fotografías: Lázaro Entrenas Martínez.

Más al este aún, se alza la Sierra de los Puntales, ya en Obejo. Si bien destaca por sus grandes extensiones de pinar de repoblación, eucaliptos y olivares serranos, llama la atención el hecho de que muchas de las cumbres se encuentren prácticamente deforestadas (figura 10). Al ser esta una zona muy azotada por los incendios forestales en el pasado (Suerte Alta, Choza Redonda, etc.), esto podría ser indicio de que los pinares tapizaban la sierra y la frecuente incidencia del fuego acabó por eliminarlos, mientras que los Quercus de las zonas bajas, más resilientes, sobrevivieron. 


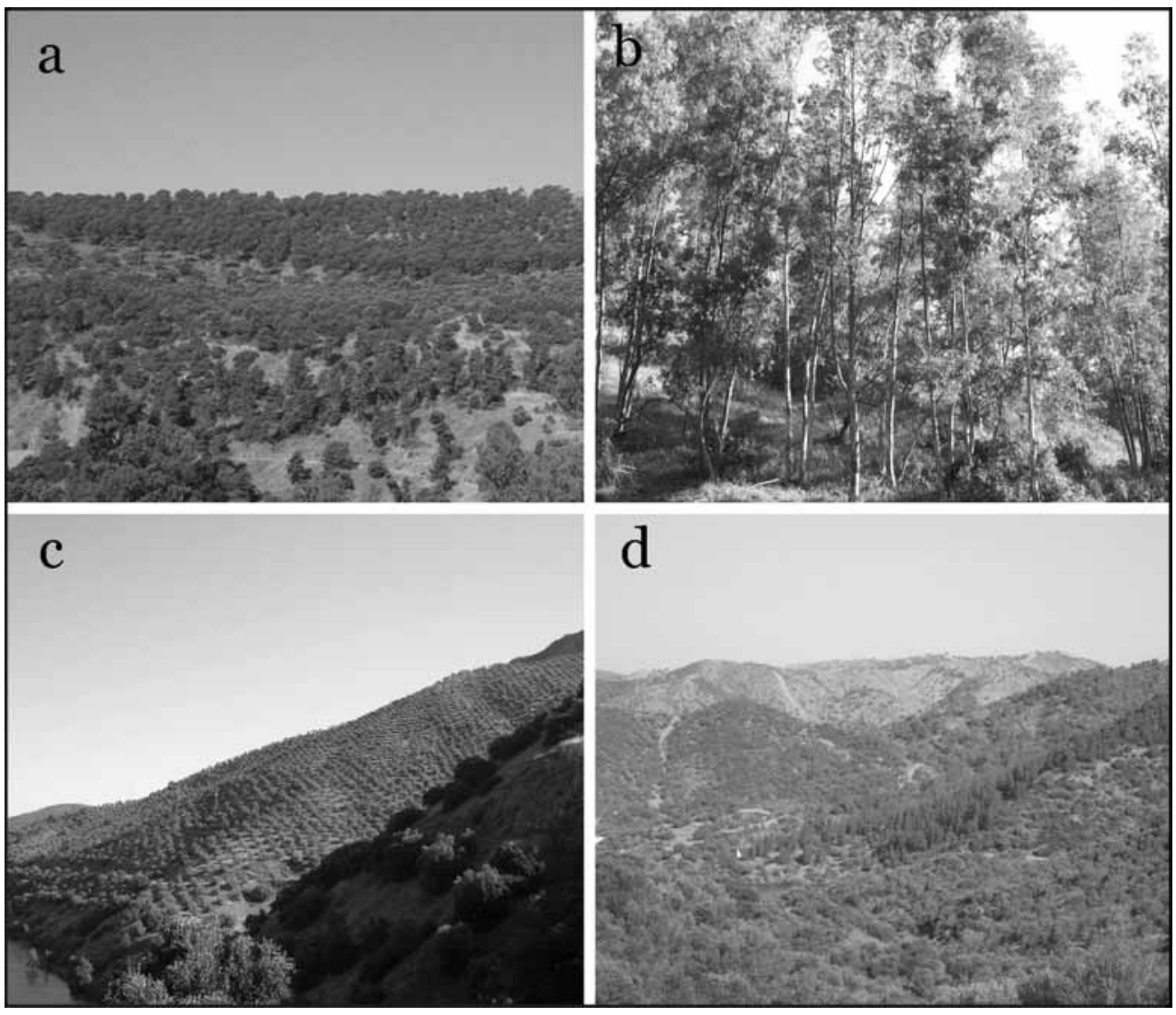

Figura 10. Sierra de los Puntales, Obejo. a) Pinar de repoblación en las proximidades del embalse del Guadalmellato. b) Bosque de eucaliptos. c) Olivar de ladera. d) Cumbres deforestadas. Autor de las fotografías: Lázaro Entrenas Martínez.

En cuanto a las amplias zonas desarboladas en el sector más septentrional del Valle del Guadiato, no tenemos datos suficientes para afirmar categóricamente que sean consecuencia de los distintos regímenes de fuego que hayan ido sucediéndose. Sin embargo, podemos suponer que el fuego se haya empleado como herramienta deforestadora y para renovar el pasto. Topónimos como El Alcornocal (donde aún se conserva el bosque mediterráneo de encinas y alcornoques) o Argallón (uno de los apelativos de la encina, derivado de agalla), aldeas de Fuente Obejuna, pueden considerarse vestigios de formaciones vegetales pretéritas. 


\section{CONCLUSIONES}

No se puede establecer, a priori, una correlación directa entre zonas de riesgo actuales e incidencia del fuego forestal histórico, entre otras cuestiones debido a los numerosos y complejos factores que intervienen en la evolución del paisaje forestal y los regímenes de fuego, así como a las interrelaciones que se dan entre los mismos. Sin embargo, el registro histórico de incendios pone de manifiesto que el fuego no es un fenómeno de reciente aparición en la comarca del Valle del Guadiato, ni como elemento de riesgo, ni como herramienta de gestión, sino que tuvo una importante presencia ya durante el siglo XIX así como a principios del XX; además, la abundancia de dehesas junto con la densidad de la red de vías pecuarias, da una idea de la relevancia del fuego como herramienta para, entre otros fines, abrir claros el bosque y mantener pastos en tiempos aún más antiguos.

Por otro lado, se ha constatado también que el régimen del fuego (intensidad, frecuencia, distribución espacial, causalidad, etc.) ha variado a lo largo del tiempo, hasta alcanzar su configuración actual. Como se ha visto, el número de incendios ocurridos cada año era menor durante el siglo XIX y el primer tercio del XX que en las últimas décadas $\mathrm{y}$, si bien la magnitud media de los mismos era mayor, no se producían los grandes incendios forestales que han llegado recientemente incluso a superar las 500 ha de superficie afectada. El abandono de tierras agrícolas experimentado en las últimas décadas ha resultado en la ruptura del mosaico de usos y en la acumulación de combustible en amplias extensiones, lo que hace que los incendios alcancen una magnitud e intensidad desproporcionada cuando escapan al control de los medios de extinción.

Asimismo, la aparición de nuevas demandas, usos y expectativas de la población en cuanto a los espacios forestales ha llevado a la aparición de nuevos territorios de riesgo, como por ejemplo las interfaces urbano-forestales, al aumento de las fuentes de ignición, así como a los cambios observados en los patrones de distribución espacial.

A pesar de la escasez de datos paleoecológicos relativos a la zona de estudio, que nos ha impedido llevar a cabo una reconstrucción de la evolución climática, de la composición del paisaje vegetal, así como de la actividad del fuego a lo largo del holoceno, el estudio y tratamiento de la información obtenida a través de distintas fuentes documentales históricas y estadísticas ha aportado conocimiento sobre la composición y estructura de los bosques y los regímenes del fuego durante los siglos XIX y XX. La investigación desarrollada se puede trasladar a otros territorios, completando y contrastando los resultados obtenidos, y obteniendo así información que puede resultar de gran valor para alimentar modelos de simulación climática y de incendios que permitan plantear escenarios futuros.

Queda pues abierta la puerta a una línea de investigación aún poco explotada y que ofrece muchas posibilidades de aplicación para la gestión de los espacios forestales y del riesgo de incendios. 


\section{REFERENCIAS}

\subsection{BIBLIOGRAFÍA}

AGNOLETTI, M. (ed., 2006): The conservation of cultural landscapes, CABI Publishing, International, Nosworthy Way, Wallingford, Oxon, UK, pp. 197-210.

JUNTA DE ANDALUCÍA: Orden de 14 de marzo de 2003, por la que se aprueba el mapa comarcal de Andalucía a efectos de planificación turística y deportiva. Boletín Oficial de la Junta de Andalucía, Sevilla, 27 de marzo de 2003, nº 59, pp. 6428-6434.

ARAQUE JIMÉNEZ, E. (coord., 1999): Incendios históricos. Una aproximación multidisciplinar. Universidad Internacional de Andalucía, Baeza.

ARAQUE JIMÉNEZ, E., SÁNCHEZ JIMÉNEZ, J.D. MOYA GARCÍA, E., PULIDO MÉRIDA, R. Y GARRIDO ALMONACID, A. (2000): Jaén en llamas. Presencia histórica de los incendios forestales en los montes provinciales. Instituto de Estudios Giennenses, Jaén.

CARCAILlET, C., ALMQUIST, H., ASNOG, H., BRADSHAW, R.H.W., CARRIÓN, J.S., GAILLARD, M.J., GAJEWSKI, K., HAAS, J.N., HABERLE, S.G., HADORN, P., MÜLLER, S.D., RICHARD, P.J.H., RICHOZ, I., RÖSCH, M., SÁNCHEZ GOÑI, M.F., VON STEDINGK, H., STEVENSON, A.C., TALON, B., TARDY, C., TINNER, W., TRYTERUD, E., WICK, L. \& WILLIS, K.J. (2002): "Holocene biomass burning and global dynamics of the carbón cycle", en: Chemosphere $\mathrm{n}^{\circ}$ 49, pp. 845-863, Elsevier, Amsterdam.

CARRIÓN, J.S. Y VAN GEEL, B. (1999): “Fine-resolution Upper Weichselian and Holocene palynological record from Navarrés (Valencia, Spain) and a discussion about factors of Mediterranean forest succession", en: Review of Palaeobotany and Palynology n ${ }^{\circ} 106$, pp. 209-236, Elsevier, Amsterdam.

CARRIÓN, J.S. (2002): "Patterns and processes of Late Quaternary environmental change in a montane region of southwestern Europe", en: Quaternary Science Reviews n²1, pp. 2047-2066, Elsevier, Amsterdam.

CARRIÓN, J.S., FUENTES, N., GONZÁLEZ-SAMPÉRIZ, P., SÁNCHEZ QUIRANTE, L., FINLAYSON, J.C., FERNÁNDEZ, S. \& ANDRADE, A. (2007): "Holocene environmental change in a montane región of Southwestern Europe with a long history of human settlement", en: Quaternary Science Reviews n 26, pp. 1455-1475, Elsevier, Amsterdam.

CARRIÓN, J.S., FERNÁNDEZ, S., JIMÉNEZ-MORENO, G., FAUQUETTE, S., GIL-ROMERA, G., GONZÁLEZ-SAMPÉRIZ, P. \& FINLAYSON, C. (2010a): "The historical origins of aridity and vegetation degradation in southeastern Spain", en: Journal of Arid Environments n ${ }^{\circ} 74$, pp. 731-736, Elsevier, Amsterdam. 
CARRIÓN, J.S., FERNÁNDEZ, S., GONZÁLEZ-SAMPÉRIZ, P., GIL-ROMERA, G., BADAL, E., CARRIÓN-MARCO, Y., LÓPEZ-MERINO, L., LÓPEZ-SÁEZ, J.A., FIERRO, E. \& BURJACHS, F. (2010b): "Expected trends and surprises in the Lateglacial and Holocene vegetation history of the Iberian Peninsula and Balearic Islands", en Review of Palaeobotany and Palynology, doi:10.1016/j.revpalbo.2009.12.007, Elsevier, Amsterdam.

CLÉMENT, V. (2002): De la marche-frontière au pays-des-bois: forêts, sociétés paysannes et territoires en vieille-castille (XI $-X X^{e}$ siècle). Casa de Velázquez, Madrid.

COllazOS, J.M. Y MORELlA, A., (1998): Nuevo atlas de Córdoba. Córdoba, Diario Córdoba.

DÍAZ FERNÁNDEZ, P.M., (1992): Historia de la vegetación en Sierra Madrona y Su entorno: una contribución a su estudio. Universidad Complutense de Madrid, Madrid. Documento inédito.

DOCTOR CABRERA, A.M. (1991): Los incendios forestales en la provincia de Córdoba. Junta de Andalucía, Córdoba.

DORADO VALIÑO, M., VALDEOLMILLOS RODRÍGUEZ, A., RUIZ ZAPATA, M.B., GIL GARCÍA, M.J. \& DE BUSTAMANTE GUTIÉRREZ, I. (1999): "Evolución climática durante el Holoceno en la cuenca alta del Guadiana (submeseta sur ibérica)", Cuaternario y Geomorfología, 13 (1-2), pp. 19-32, Sociedad Española de Geomorfología, Oviedo.

FONTUGNE, M., ARNOLD, M., LABEYRIE, L., PATERNE, M., CALVERT, S., DUPLESSY, J.C. (1994): "Palaeoenvironment, sapropel chronology and Nile River discharge during the last 20000 years as indicated by deep sea sediment records in the eastern Mediterranean", en: BAR-YSEF, O., KRA, R.S. (Eds.), Late Quaternary Chronology and Paleoclimates of the Eastern Mediterranean. Radiocarbon, pp. 75-88, University of Arizona, Tucson.

GALIANA, L.

JALUT, G. et al. (2009): "Holocene circum-Mediterranean vegetation changes: Climate forcing and human impact", en: Quaternary International, $\mathrm{n}^{\circ} 200$, pp. 4-18, Elsevier, Amsterdam.

LÓPEZ-SÁEZ, J.A. et al. (1998): "Remarques paléoécologiques à proos de quelques palynomorphes non-polliniques provenant de sédiments quaternaires en France", en: Revue de Paléobiologie n 17 (2), pp. 445-459, Museum d'histoire naturelle de la Ville de Geneve, Ginebra.

LÓPEZ-SÁEZ, J.A. et al. (2007): “Origen prehistórico de la dehesa en Extremadura: Una perspectiva paleoambiental”, en: Revista de estudios extremeños, $\mathrm{n}^{\circ}$ 63, pp. 493-510, Diputación de Badajoz, Badajoz. 
MAYEWSKI, P.A. et al. (2004): "Holocene climate variability", en: Quaternary Research $\mathrm{n}^{\mathrm{o}}$ 62, pp. 243-255, Elsevier, Amsterdam.

MAZZOLENI, S. DI PASQUALE, G., MULLIGAN, M. DI MARTINO, P. REGO, F. (ed.), (2004): Recent Dynamics of the Mediterranean Vegetation and Landscape. Chichester (Reino Unido), Wiley \& Sons, Reino Unido.

MÉTAILLÉ, J.P. (coord.) (1992): Protoindustries et histoire des forêts. Actes du Colloque tenu à la Maison de la Forêt. Université de Toulouse-Le Mirail, Toulouse.

MONTIEL MOLINA, C. (2003): "El patrimonio forestal mediterráneo: componentes y valoración", en: Bois\&Forêts des Tropiques, no 276 (2), pp. 73-83, Éditions Lavoisier, Francia.

MÜLLER-KARPE, H. (1992): Storia dell'età della pietra, Mondadori, Milán.

PÉREZ, F.F. y BOSCOLO, R. (eds.) (2010): Clima en España: pasado, presente y futuro. Red temática CLIVAR España. Documento electrónico.

PYNE, S.J. (1997): Vestal Fire. An Environmental History, Told through Fire, of Europe and Europe's Encounter with the World. University of Washington Press, Seattle and London.

PIUSSI, P., en: A. TELLER, P. MATHY y J.N.R. JEFFERS (eds.) (1992): Responses of Forest Ecosystems to Environmental Changes, pp. 298-309, Elsevier, Amsterdam.

PONS, A., REILLE, M. (1988): “The Holocene and Upper Pleistocene pollen record from Padul (Granada, Spain): a new study", en: Palaeography, Palaeoclimatology, Palaeoecology n ${ }^{\circ}$ 66, pp- 243-263, Elsevier, Amsterdam.

SEVILLA MARTÍNEZ, F. (2008): Una teoría ecológica para los montes ibéricos. IRMA - Instituto de Restauración y Medio Ambiente, León.

SCHILMAN, B., et al. (2001): "Global climate instability reflected by Eastern Mediterranean marine records during the late Holocene", en: Palaeography, Palaeoclimatology, Palaeoecology, $\mathrm{n}^{\circ}$ 176, 157-176, Elsevier, Amsterdam.

SCHÜLE, W., en J.C. GOLDAMMER (ed.), (1990): "Fire in the Tropical Biota. Ecosystem Processes and Global Challenges", en: Ecological Studies, n ${ }^{\circ}$ 4, pp. 273-218, Springer, Países Bajos.

SOLANO MÁRQUEZ CRUZ, F. (coord.) (1992): Los Pueblos de Córdoba. 5 Volúmenes. Caja Provincial de Ahorros de Córdoba, Córdoba.

STEVENSON, A.C. (2000): "The Holocene Forest History of the Montes Universales, Teruel, Spain.", en: The Holocene $n^{\circ}$ 10, pp. 603-610, SAGE Publications, Londres. 
TINNER, W., CONEDERA, M., AMMAN, B., GAGGELER, H. W., GEYDE, S., JONES, R. and SAGESSER, B. (1998). "Pollen and charcoal in lake sediments compared with historically documented forest fires in southern Switzerland since AD 1920", en: The Holocene n 8, pp. 31-42, SAGE Publications, Londres.

\subsection{FUENTES DE INTERNET}

Agencia Estatal de Meteorología: http://www.aemet.es. Última consulta 19 de abril de 2010.

Biblioteca Nacional de España; hemeroteca digital: http://hemerotecadigital.bne.es/cgi-bin/Pandora/. Última consulta 7 de mayo de 2010.

Centro Español de Metrología. http://www.cem.es/cem/es_ES/metrologia/metrologia.jsp?idprovincia $=0$

Ferropedia, enciclopedia sobre ferrocarriles en español. http://ferrocarriles.wikia.com/. Última consulta 30 de marzo de 2010.

Junta de Andalucía: Consejería de Medio Ambiente. http://www.juntadeandalucia.es/medioambiente/site/web/. Última consulta 2 de mayo de 2010.

Junta de Andalucía: Sistema de Información Multiterritorial. http://www.juntadeandalucia.es:9002/sima/index.htm. Última consulta el 2 de mayo de 2010.

Portal de la Mancomunidad del Valle del Guadiato.

http://www.guadiato.es. Última consulta 2 de mayo de 2010.

Nodo de la Red de Información Ambiental de Andalucía.

http://www.juntadeandalucia.es/medioambiente/site/web/rediam/. Última consulta 23 de Abril de 2010.

\subsection{ABREVIATURAS}

ADCO: Archivo General de la Diputación Provincial de Córdoba.

AMAPA: Archivo del Ministerio de Agricultura, Pesca y Alimentación.

AMCO: Archivo Histórico Municipal de Córdoba.

BOJA: Boletín Oficial de la Junta de Andalucía.

CCHS-CSIC: Centro de Ciencias Humanas y Sociales, Consejo Superior de Investigaciones Científicas. 